later elections the error has been reduced to $2 \frac{1}{2}$ per cent. His method is to choose a sample of about 30,000 , which is divided up for age, income, sex, and geographical location in the same proportions as the total population of the United States. Similar predictions are made for local elections in Great Britain by the British Institute of Public Opinion, using a sample of 1,500-2,000. The procedure seems very satisfactory for forecasting election results, but for estimating public opinion on such questions as confidence in the Government, statistical methods may be very misleading. In a paper entitled "The Limitations of Statistics in the Field of Public Opinion Research", read before the Manchester Statistical Society on April 14, Mr. J. G. Ferraby argues that for many purposes the qualitative methods adopted by Mass Observation are preferable. These rely largely on a panel of voluntary observers, who answer written questions drawn up by headquarters, keep diaries, forward letters received by them which comment on general topics, and report conversations, including some not intended to be overheard. It is claimed that this method subordinates accuracy of detail to accuracy in presenting a true picture of the whole. It is not explained how the accuracy of the observers or the truth of the picture is checked.

\section{Earthquakes Registered at Kew and Stonyhurst}

SEven strong earthquakes were registered at Kew Observatory during the month of May 1943. The first was on May 2, recorded at 0lh. $10 \mathrm{~m}$. 17s. U.T., and has been reported as having been felt in Württemberg in Germany. The second, also on May 2, began recording at $17 \mathrm{~h}$. $30 \mathrm{~m}$. 11s. U.T. from an epicentre some $8,700 \mathrm{~km}$. distant, and attained a maximum ground amplitude of $180 \mu$ at Kew at $17 \mathrm{~h} .58 \mathrm{~m}$. 23s. U.T. The third, on May 3 , began recording at $02 \mathrm{~h}$. $13 \mathrm{~m}$. 0ls. U.T. from an epicentre some $11,000 \mathrm{~km}$. distant, and attained a maximum ground amplitude at Kew of $200 \mu$ at $03 \mathrm{~h} .03 \mathrm{~m}$. 15s. U.T. The fourth, not so large, was recorded at $09 \mathrm{~h} .15 \mathrm{~m}$. 54s. U.T. on May 20, and the fifth, on May 22, recorded at 22h. $10 \mathrm{~m}$. 37s. U.T., has been reported as having been felt in Italy. The sixth was by far the largest of the month. It was recorded at Kew at $23 \mathrm{~h}$. $21 \mathrm{~m}$. 54s. U.T. on May 25, and from the provisional interpretation of the record came from an epicentre some $12,500 \mathrm{~km}$. distant. It attained maximum ground amplitude at Kew of $340 \mu$. At Stonyhurst the shock was also recorded at $23 \mathrm{~h}$. $21 \mathrm{~m}$. 54s. U.T. on May 25, and from a tentative interpretation of the record, came from an epicentre some $105^{\circ}$ distant. The seventh earthquake was recorded at Kew at 00h. 27m. 01s. U.T. on May 28, and attained a maximum ground amplitude at Kew of $35 \mu$. It appeared to come from an epicentre somewhere near the one first recorded in the month. This shock was also recorded at Stonyhurst at approximately $00 \mathrm{~h}$. $28 \mathrm{~m}$. 20s. U.T. The German radio reported an earthquake at about this time, the epicentral region being west of Balingen near Stuttgart. Some roofs and chimneys are stated to have collapsed, causing injuries to people, and "strange glows" are reported to have been observed. The shock was also reported felt in Württemberg and Baden, in Oberade, the Bodensee and in Alsace. Tremors were felt in Switzerland, most strongly in the cantens of Schaffhausen and Thurgau. The earthquake was apparently preceded by a foreshock, which was felt at places in south-west Germany including Frankforton-Main; but this foreshock was not recorded with any intensity in England. The main shock was also recorded at West Bromwich, on the seismograph belonging to Mr. J. J. Shaw.

\section{The Franklin Institute : Medal Awards}

THE following medals of the Franklin Institute, Philadelphia, were awarded on April 21 : Franklin Medal and Honorary Membership to Prof. Harold C. Urey, professor of chemistry in Columbia University, for his discovery and production of heavy hydrogen, which has proved of immense importance in furthering research in chemistry, physics, and biology ; and to Dr. George Washington Pierce, for his development of "electrically squeezed" quartz crystals used to narrow the range of radio frequencies. The use of this principle in obtaining accurate oscillations has facilitated the construction of the most precise electric clocks. Elliot Cresson Medal to Prof. Charles M. Allen of Worcester Polytechnic Institute. His contribution to the field of hydraulics is a more rapid method of measuring the flow of water by adding a known amount of salt to the water and noting the time required for it to pass electrodes inserted in the pipe lines down-stream.

Howard A. Potts Medal to Dr. Don Francisco Ballen for restoring a valuable natural resource of his country to productivity; and to Dr. Paul R. Heyl of the National Bureau of Standards for his theoretically important formula to determine the constant of gravitation. Frank P. Brown Medal (for achievements in building and allied industries) posthumously to Mr. Albert Kahn, Detroit architect. Edward Longstreth Medals (jointly) to Mr. Robert Griffin $\mathrm{De}$ La Mater and Mr. William Schwemlein. Their design and successful application of a fluid brake has made practical the drilling of wells to great depths, with increased safety to life and property. John Price Wetherill Medal to Robert Howland Leach. George $R$. Henderson Medal to Harry Miller Pflager, senior vicepresident of the General Steel Castings Company. A Certificate of Merit to Carl S. Hornberger. The 1943 Louis Edward Levy Medal (for the best paper published in the Journal of the Franklin Institute during 1942) to Anders Henrik Bull of Forest Hills, N.Y., for his paper, "Soil Pressure Distribution along Flexible Foundations".

\section{Institution of Electrical Engineers}

IN collaboration with the British Red Cross Society arrangements were made by the Institution of Electrical Engineers for British prisoners of war in Germany to sit for the associate membership examinations held in May and November, 1942. There were nineteen such candidates who took the examination, or parts thereof, on one or other of the two dates, seven of whom were successful in passing Parts $I$ and II, three in passing Part I only, and one Part II only. Five others passed in single subjects, a special concession having been granted to prisoners of war to take one subject at a time if they so desired. A commendably high standard of marks was reached by the candidates. Seventeen candidates in Germany entered for the May 1943 examination.

\section{ASLIB Training Course in Special Librarianship}

Owing to the fact that many skilled and experienced librarians have been called up for various forms of national service, there is now great difficulty 
in operating special libraries and information bureaux to the required standard of efficiency with the untrained and inexperienced assistant staff available. To meet this difficulty, the Association of Special Libraries and Information Bureaux (ASLIB) organized an emergency course of training during the spring of 1943. This has proved to be such a success that the course is being repeated in the autumn and, in addition, an intensive course is being given as a week's summer school (August 9-14) for those who, because of distance or other reasons, cannot attend weekly lectures. The fee for the course is five guineas. Applications to attend should be made as soon as possible to ASLIB, 31 Museum Street, London, W.C.I.

\section{Summer School in X-Ray Crystallography}

A sUMmer school in X-ray crystallography applied to industrial problems is being arranged by the Departments of Physics and of Mineralogy and Petrology in co-operation with the Board of Extra. mural Studies of the University of Cambridge, and will be under the direction of Dr. W. A. Wooster, University lecturer in the Department of Mineralogy and Petrology, and of Dr. H. Lipson, assistant in experimental research in crystallography. The number of practical applications of X-ray crystal analysis in industry has greatly increased, and it is quite probable that the usefulness of X-ray crystallography in the solution of industrial problems is not fully appreciated by technical men attached to industrial organizations. There is a growing need for the proper training of such technical men in this type of work, even though a working knowledge of it may have been acquired already. The chief aim of the summer school will be to give a training in the fundamentals of the subject, to bring workers into touch with the wide range of methods used, to teach them the newest techniques, and to indicate the many types of industrial problems in which this work can be used with advantage. Emphasis will be laid on practical work both with apparatus and in the interpretation of various kinds of X-ray photographs. The course is designed to extend from September 6 until September 18, but it will be possible to attend for either week only. In view of the present shortage of staff, apparatus and materials, the numbers attending the school will be limited; application to attend must be made before July 26 . Further in formation can be obtained from the Secretary of the Board of Extra-murall Studies, Stuart House, Mill Lane, Cambridge.

\section{University of London}

THE title of professor emeritus of the history of medicine in the University of London has been conferred on Dr. Charles Singer on his retirement from the professorship of the history of medicine at University College.

The degree of D.Sc. has been conferred on Mr. F. R. Goss (Imperial College of Science and Technology); Mr. S. H. Harper (Imperial College of Science and Technology); Miss Emmy Klieneberger (Lister Institute of Preventive Medicine); Mr. W. T. Russell, a 'recognised teacher' at the London School of Hygiene and Tropical Medicine; Mr. T. E. Wallis, reader at the College of the Pharmaceutical Society; London.

\section{Physical Society: Charles Chree Medallist}

The Charles Chree Medal and Prize are provided by the income from a fund given to the Physical Society in 1939 by Miss Jessie S. Chree, of Edinburgh, in memory of her brother, Dr. Charles Chree, a former president of the Society and superintendent of the Kew Magnetic Observatory. The Prize and Medal are awarded biennially in recognition of distinguished research in terrestrial magnetism, atmospheric electricity or cognate subjects, in which Dr. Chree was specially interested. The Council of the Society made the first award to Prof. Sydney Chapman in 1941 for his work in the first of these fields. The Medal and Prize for 1943 have been awarded to Prof. (now Brigadier) Basil F. J. Schonland, director of the Bernard Price Institute of Geophysics, Johannesburg, in recognition of his valuable researches in the second field (see Nature, February 20, p. 218). The presentation will be made at a meeting of the Society at the Royal Institution on July 16, when Brigadier Schonland will deliver the second Charles Chree Lecture, taking as his subject "Thunderstorms and their Electrical Effects".

\section{Announcements}

IN accordance with the terms governing the appointment of the Parsons Memorial lecturers, the lecture for 1943 is to be given under the auspices of the Physical Society. It will be delivered early in the autumn by Lord Rayleigh. The date and further particulars will be announced in due course.

THE governing body of the Imperial College of Science and Technology has elected to Imperial College fellowships the following old students of the college : Dr. F. W. Lanchester, Dr. J. G. Lawn, Dr. F. C. Lea, Mr. F. Twyman, and Mr. H. G. Wells.

DR. R. R. Mrmms has been appointed lecturer in physics in the University of Birmingham to succeed Dr. Guy Barlow, who is retiring after forty years service. Dr. P. B. Moon has been given the title of reader in atomic physics.

The University of Aberdeen has conferred the honorary degree of LL.D. on Prof. D. M. S. Watson, Jodrell professor of zoology and comparative anatomy, University College, London. The degree of D.Sc. has been awarded to W. Burns, for a thesis on "An Oscillographic Study of the Activity in Nerves associated with the Viscera"; and on Dr. R. D. Stuart, for a thesis on "A Study of Leptospirosis in the South.West of Scotland with special reference to Laboratory Investigation, Epidemiology and Specific Prophylaxis".

Dr. W. E. LE B. Dramond, assistant secretary of the Institution of Gas Engineers since I937, has been appointed general manager of the British Plastics Federation.

Applicarions for the conditions of the competition for the Jones-Bateman Cup offered triennially for original research in fruit culture which has added to our knowledge of cultivation, genetics, or other relative matters, may be had on application to the Secretary, Royal Horticultural Society, Vincent Square, Westminster, London, S.W.1. 